\title{
Spatial pattern of plant species diversity and the influencing factors in a Gobi Desert within the Heihe River Basin, Northwest China
}

\author{
ZHANG Pingping ${ }^{1,2}$, SHAO Ming' an ${ }^{1,2,3^{*}}$, ZHANG Xingchang ${ }^{1,2}$ \\ ${ }^{1}$ Institute of Soil and Water Conservation, Northwest A\&F University, Yangling 712100, China; \\ ${ }^{2}$ State Key Laboratory of Soil Erosion and Dryland Farming on the Loess Plateau, Institute of Soil and Water Conservation, \\ Chinese Academy of Sciences and Ministry of Water Resources, Yangling 712100, China; \\ ${ }^{3}$ Key Laboratory of Ecosystem Network Observation and Modeling, Institute of Geographic Sciences and Natural Resources \\ Research, Chinese Academy of Sciences, Beijing 100101, China
}

\begin{abstract}
Understanding the spatial pattern of plant species diversity and the influencing factors has important implications for the conservation and management of ecosystem biodiversity. The transitional zone between biomes in desert ecosystems, however, has received little attention in that regard. In this study, we conducted a quantitative field survey (including 187 sampling plots) in a 40- $\mathrm{km}^{2}$ study area to determine the spatial pattern of plant species diversity and analyze the influencing factors in a Gobi Desert within the Heihe River Basin, Northwest China. A total of 42 plant species belonging to 16 families and 39 genera were recorded. Shrub and semi-shrub species generally represented the major part of the plant communities (covering $90 \%$ of the land surface), while annual and perennial herbaceous species occupied a large proportion of the total recorded species (71\%). Patrick richness index (R), Shannon-Wiener diversity index $\left(H^{\prime}\right)$, Simpson's dominance index $(D)$, and Pielou's evenness index $(J)$ were all moderately spatially variable, and the variability increased with increasing sampling area. The semivariograms for $\mathrm{R}$ and $H^{\prime}$ were best fitted with Gaussian models while the semivariograms for $D$ and $J$ were best fitted with exponential models. Nugget-to-still ratios indicated a moderate spatial autocorrelation for $R, H^{\prime}$, and $D$ while a strong spatial autocorrelation was observed for $J$. The spatial patterns of $\mathrm{R}$ and $H^{\prime}$ were closely related to the geographic location within the study area, with lower values near the oasis and higher values near the mountains. However, there was an opposite trend for $D$. R, $H^{\prime}$, and $D$ were significantly correlated with elevation, soil texture, bulk density, saturated hydraulic conductivity, and total porosity $(P<0.05)$. Generally speaking, locations at higher elevations tended to have higher species richness and diversity and the higher elevations were characterized by higher values in sand and gravel contents, bulk density, and saturated hydraulic conductivity and also by lower values in total porosity. Furthermore, spatial variability of plant species diversity was dependent on the sampling area.
\end{abstract}

Keywords: species diversity; spatial heterogeneity; environmental factors; Gobi Desert; transitional zone

Citation: ZHANG Pingping, SHAO Ming'an, ZHANG Xingchang. 2017. Spatial pattern of plant species diversity and the influencing factors in a Gobi Desert within the Heihe River Basin, Northwest China. Journal of Arid Land, 9(3): 379-393. doi: $10.1007 / \mathrm{s} 40333-017-0056-9$

\section{Introduction}

The diversity of plant species, representing the biodiversity at the species level, has been one of

*Corresponding author: SHAO Ming'an (E-mail: mashao@ms.iswc.ac.cn)

Received 2016-06-23; revised 2016-12-28; accepted 2017-01-18

(C) Xinjiang Institute of Ecology and Geography, Chinese Academy of Sciences, Science Press and Springer-Verlag Berlin Heidelberg 2017 
the foci in the research of ecosystem diversity (Wilson et al., 1990; Xu et al., 2011). Plant species diversity not only can reflect species richness or abundance, variation degree of plant communities or vegetation, and evenness in plant communities or habitats, but also can quantitatively express the characteristics of plant communities and ecosystems (Ricotta and Avena, 2003). The competitive ability of plant species is often differentiated in nature along environmental gradients (Lundholm and Larson, 2003). Spatially varying environments can affect plant-resource interactions or the outcome of competition (Collins and Wein, 1998), aggregating species and species diversity in patches or forming distinct gradients or other kinds of spatial patterns (Irl et al., 2015; Fibich et al., 2016). Thus, different environmental factors can influence the patterns of plant species diversity, community structure, and vegetation type through various mechanisms (Costanza et al., 2011). Multiple overlapping and interacting environmental factors within a landscape are often simultaneously in the action (Slaton, 2015), highlighting the needs for studying the spatial pattern of plant species diversity and also for identifying the major drivers of the pattern.

The spatial pattern of plant species diversity is related to a variety of abiotic and biotic factors (Fu et al., 2004; Huerta-Martínez et al., 2004; Zuo et al., 2008; Xu et al., 2011; Irl et al., 2015). The factors influencing the spatial pattern of plant species diversity vary at different spatial scales (Zuo et al., 2012). For example, the spatial pattern of plant species diversity is mainly regulated by climatic factors (e.g., temperature and precipitation) and geographic factors (e.g., latitude and longitude) at a large geographical scale (Thuiller et al., 2005; Zhang et al., 2016), whereas it mainly depends on edaphic factors at a small geographical scale (Yang et al., 2009). Furthermore, plant species diversity can also be associated with a specific environmental factor in different manners, e.g., positive, negative, hump-shaped, U-shaped, and even no relationship (Peet, 1981; Wilson and Sykes, 1988; Vázquez García and Givnish, 1998; Rodríguez-Castañeda et al., 2010; Pellissier et al., 2012). It should be particularly noted that contrary conclusions were often drawn in different regions or even within the same region. For example, Wang et al. (2007) indicated that plant species diversity was significantly correlated with soil bulk density, but Zhao et al. (2009) found that plant species diversity was not significantly correlated with soil bulk density. Another example was elevation-related. Adams and Zhang (2009) observed a positive relationship between plant species diversity and elevation in eastern North America, while Zhang et al. (2011) found a negative relationship in this region. All in all, no consensus has been reached. Thus, more studies are needed to better understand the compositions, changes, and developments of plant communities and to provide a scientific basis for ecological conservation and management.

Geostatistics provides a set of statistical tools for describing and modelling the spatial patterns of biotic and abiotic variables by analyzing the spatial dependence and the autocorrelation of the attributes and by estimating the attributes at unsampled locations using limited information (Matheron, 1963). This methodology has been widely applied in ecology and the successful applications include analyzing the spatial variability and distribution of soil properties (Burgess and Webster, 1980a, b), predicting plant cover (Zare-Mehrjardi et al., 2010; Liu et al., 2016) and aboveground biomass ( $\mathrm{Du}$ et al., 2010), and characterizing the spatial structures of plant communities (Wallace et al., 2000). This approach, however, is rarely, if ever, used to model the spatial pattern of plant species diversity.

The region of the Gobi Desert in the northern Linze County of Gansu Province in China (i.e., the middle reaches of the Heihe River Basin) is located between an artificial oasis and a natural desert. Due to the dual influences of intensive human activities and harsh natural conditions, this region is rather ecological sensitive and fragile. The importance of the transitional zone between oasis and desert can be well illustrated by following two examples. First, aboveground vegetation in this transitional zone can weaken the wind-blown sand. Second, belowground vegetation (i.e., roots) can fix the soil particles. Thus, vegetation in this region plays a key role in maintaining the stability of the oasis ecosystem. The spatial pattern of the dominant shrub populations (He and Zhao, 2004) and the dependence of plant species diversity on scale (He et al., 2006) have been in-depth studied in this important ecological region, but information on the spatial pattern of plant species diversity as well as the influencing factors is still lacking. 
We therefore conducted a quantitative survey for the aboveground vegetation and environmental factors in this Gobi Desert region. The specific objectives were: (1) to identify the composition and diversity of plant species; (2) to determine the spatial pattern of plant species diversity; and (3) to analyze the influencing factors on plant species diversity. It is our hope that this study could provide the needed scientific references to ecological conservation and management for this region and also for other similar areas.

\section{Materials and methods}

\subsection{Study area}

This study was conducted in a Gobi Desert region in the middle reaches of the Heihe River Basin, Gansu Province, Northwest China (Figs. 1a and b). The study area $\left(39^{\circ} 24^{\prime}-39^{\circ} 29^{\prime} \mathrm{N}\right.$, $100^{\circ} 08^{\prime}-100^{\circ} 12^{\prime} \mathrm{E} ; 1390-1470 \mathrm{~m}$ a.s.1.), covering an area of approximately $40 \mathrm{~km}^{2}(8 \mathrm{~km} \times 5 \mathrm{~km})$, is bordered by a young oasis to the southwest, a remnant of the Qilian Mountains to the north, and an extension of the Badain Jaran Desert to the southeast (Fig. 1c). The area is characterized by a temperate arid climate with the annual mean temperature of $7.6^{\circ} \mathrm{C}$ and the mean annual precipitation of $117 \mathrm{~mm}$. It should be noted that about $65 \%$ of annual total precipitation occurred in the rainy season spanning from July to September. The mean annual pan-evaporation is 2390 $\mathrm{mm}$, and the mean annual wind speed is $3.2 \mathrm{~m} / \mathrm{s}$ (with the dominant windy days occurring between March and May). The zonal soil is classified as grey-brown desert soil (He and Zhao, 2004) and is derived from the fluvial-alluvial deposits (Su and Yang, 2008). Soil textures range from sand to clay. The study area has been fenced and protected from grazing for the purpose of vegetation restoration. Vegetation cover is spatially heterogeneous, with patches of shrubs and sub-shrubs interspersed within a matrix of bare soil.

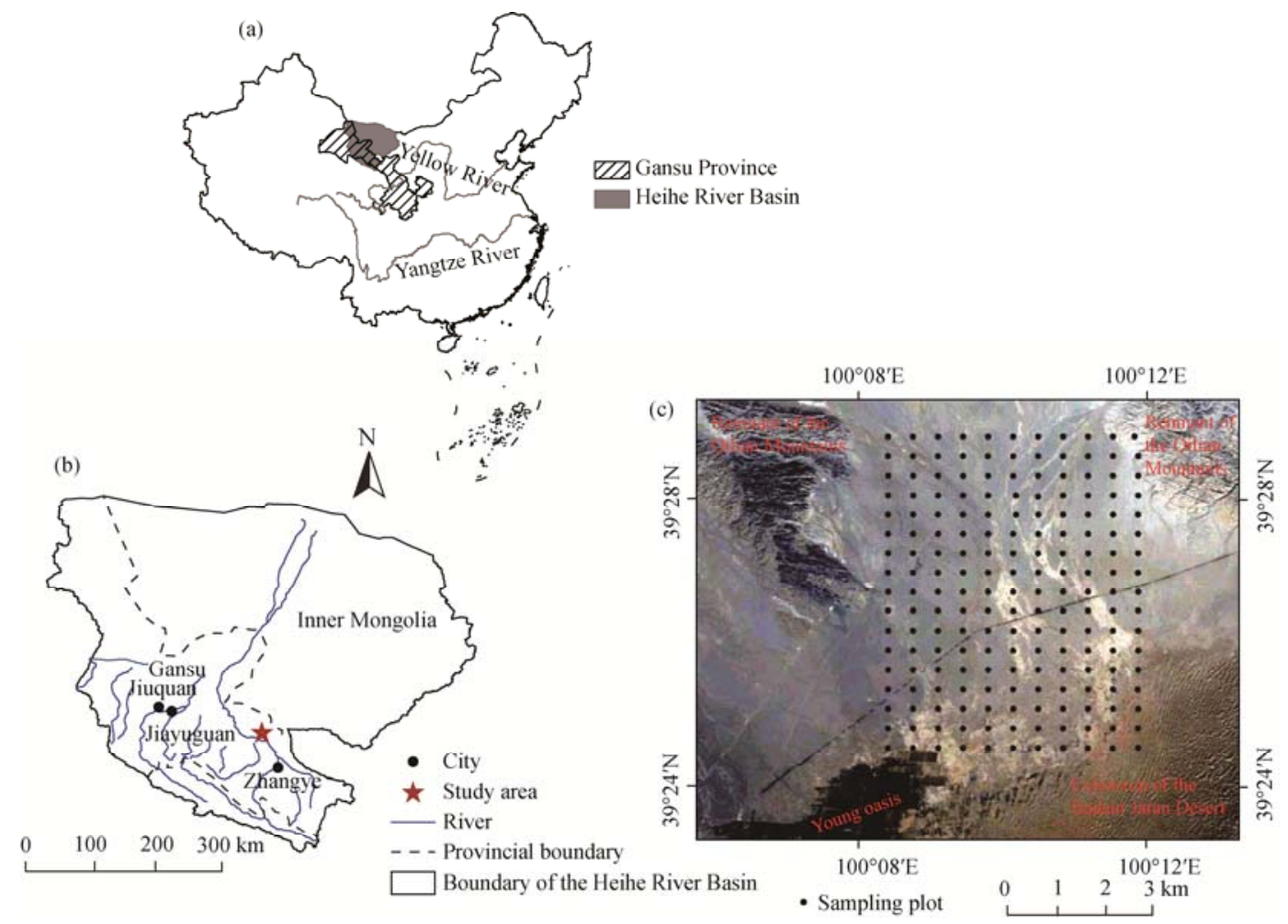

Fig. 1 Locations of the study area (a, b) and the sampling plots (c)

\subsection{Field investigation and data collection}

A quantitative vegetation survey was carried out in mid-August 2012, i.e., the vigorous growth 
period of plant species. We carried out the survey based on 187 regular grids (each area of 500 $\mathrm{m} \times 500 \mathrm{~m}$ ) and the positions were recorded with a portable Garmin GPS receiver (resolution of 3 $\mathrm{m})$. Correspondingly, a total of 187 shrub sampling plots with a distance of $\sim 480 \mathrm{~m}$ from each other were selected. The average size of each plot was $400 \mathrm{~m}^{2}(20 \mathrm{~m} \times 20 \mathrm{~m})$. In each sampling plot, three herbaceous sampling quadrats with an area of $2 \mathrm{~m} \times 2 \mathrm{~m}$ each were randomly set. All plant species were identified and recorded, and the abundance, height, and cover of each species were measured and recorded. Specifically, the abundance was determined by counting the individuals of each species; the height was measured from the soil surface to the highest point of the plant; and the cover was estimated as the percentage ratio of the crown size to the plot size for the shrub species and estimated using the visual method for the herbaceous species (Sutherland, 1999).

In each sampling plot, five soil samples were randomly collected from the upper soil layer $(0-10 \mathrm{~cm})$ and were mixed as one composite sample. Those soil samples (187 in total) were air dried, weighed, and sieved by a $2-\mathrm{mm}$ mesh. Then, each of soil samples was divided into the coarse (particle size $>2 \mathrm{~mm}$ ) and fine (particle size $\leq 2 \mathrm{~mm}$ ) fractions. The coarse samples were reweighed to determine the gravel content. The fine samples were further separated into two parts. One part was used to determine the particle-size distribution with a Mastersizer 2000 particle-size analyzer (Malvern Instruments, Malvern, England). The other was passed through a $0.25-\mathrm{mm}$ mesh and then used to determine soil organic carbon content using potassium dichromate/wet combustion (Nelson and Sommers, 1982). In each sampling plot, five soil samples (at the same locations with the above five samples) were also collected from the upper soil layer $(0-10 \mathrm{~cm})$ to determine saturated hydraulic conductivity, bulk density, and total porosity. The saturated hydraulic conductivity was measured using the constant hydraulic head method (Klute and Dirksen, 1986), and bulk density and total porosity were measured using the gravimetric method. For each plot, the five replicate measurements were averaged to reduce the influence of gravels on the measurements.

\subsection{Plant species diversity indices}

In this study, Patrick richness index $(R)$, Shannon-Wiener diversity index $\left(H^{\prime}\right)$, Simpson's dominance index $(D)$, and Pielou's evenness index $(J)$ were selected to evaluate the plant species diversity (Zhang et al., 2003).

$$
\begin{gathered}
R=S . \\
H^{\prime}=-\sum_{i=1}^{S} p_{i} \ln \left(p_{i}\right) . \\
D=\sum_{i=1}^{S} p_{i}^{2} . \\
J=H^{\prime} / \ln S .
\end{gathered}
$$

Where, $S$ is the number of species recorded in each sampling plot, and $p_{i}$ is the relative importance value of species $i$ in each sampling plot. The relative importance value of species $i$ in each sample plot was calculated as: $p_{i}=($ relative cover + relative height + relative abundance $) / 3(\mathrm{Li}$ et al., 2006).

\subsection{Statistical analyses}

Descriptive statistical analyses (including maximum, minimum, mean, median, kurtosis, skewness, standard deviation (SD), and coefficient of variation (CV)) were firstly used to identify the variation trends of plant species diversity indices. The normality of the data was tested using the one-sample Kolmogorov-Smirnov (K-S) test. It should be pointed out that the natural logarithmic transformations were applied where necessary for meeting the normality requirements of the geostatistical analyses. Furthermore, correlation analysis was used to determine the relationships between plant species diversity and environmental factors. 
Estimating the variability of plant species diversity indices at different spatial scales is important for effectively sampling vegetation in the field and accurately predicting the changes in plant species diversity. In this study, we re-sampled the subsets of plot allocations of different sizes for all sampling plots $(n=187)$ to detect the variability of plant species diversity indices associated with the size of the re-sampling area. We assigned integral multiples of $1 \mathrm{~km}$ to the east-west and north-south directions within the study area to generate two sets of options. Specifically, 5 re-sampling options were generated along the east-west direction and 8 re-sampling options were generated along the north-south direction. The random combination of these two sets of options thus yielded 40 potential re-sampling options (corresponding to 40 re-sampling areas). It should be noted that different re-sampling options may obtain the same re-sampling area, e.g., $1 \mathrm{~km} \times 4 \mathrm{~km}$ and $2 \mathrm{~km} \times 2 \mathrm{~km}$ were the same within the study area and thus they should be excluded. Totally, 24 re-sampling areas were obtained (see Zhang and Shao (2015)). The variability of plant species diversity indices in an area was calculated by averaging the coefficients of variation (CVs) of all possible re-sampling options with the same area.

Semivariograms were used to quantify the spatial dependence of plant species diversity indices and to provide the input parameters of ordinary kriging interpolation. The semivariogram can be calculated as follows (Yost et al., 1982):

$$
\gamma(h)=\frac{1}{2 N(h)} \sum_{i=1}^{N(h)}\left[Z\left(x_{i}\right)-Z\left(x_{i}+h\right)\right]^{2} .
$$

Where, $Z\left(x_{i}\right)$ and $Z\left(x_{i}+h\right)$ are observation values at positions $x_{i}$ and $x_{i}+h$, respectively; and $N(h)$ is the number of pairs of sample points separated by the lag distance $h$.

The experimental variogram was calculated for several lag distances and then were fitted with theoretical models, such as spherical, exponential, Gaussian, and linear models. Then, the best-fitted semivariogram model with the smallest residual sum of squares (RSS) and the highest coefficient of determination $\left(R^{2}\right)$ was selected. The model provided the input parameters for the ordinary Kriging interpolation to predict the spatial pattern of plant species diversity. The parameters included: (1) nugget $\left(\mathrm{C}_{0}\right)$; (2) sill $\left(\mathrm{C}+\mathrm{C}_{0}\right)$; (3) nugget ratio $\left(\mathrm{C}_{0} /\left(\mathrm{C}+\mathrm{C}_{0}\right)\right)$; and (4) range (A) (Schneider et al., 2011). The nugget $\left(\mathrm{C}_{0}\right)$ represents the undetectable measurement error, inherent heterogeneity, or the fine-scale variability. The sill $\left(\mathrm{C}+\mathrm{C}_{0}\right)$ is the upper limit of the semivariogram model, representing the total variation. The nugget ratio $\left(\mathrm{C}_{0} /\left(\mathrm{C}+\mathrm{C}_{0}\right)\right)$ can be used as a criterion for classifying the spatial autocorrelations among variables, with ratios of $<0.25$, $0.25-0.75$, and $>0.75$ representing strong, moderate, and weak spatial autocorrelations, respectively (Cambardella et al., 1994). The range (A) of spatial dependency is the separation distance at which the sill is reached. Samples separated by distances shorter than the range (A) are spatially related, whereas samples separated by distances longer than the range (A) are not spatially related.

The geostatistical analysis was performed with GS+ version 7.0 (Gamma Design Software, Plainwell, USA), and the contour maps of ordinary Kriging interpolation were produced with the GIS program ArcView version 3.3 and its extension module Spatial Analysis version 2.0 (ESRI Inc., Redlands, USA).

\section{Results}

\subsection{Plant species composition}

Plant species composition in the study area was simple, mainly with xerophytic or super-xerophytic shrubs, sub-shrubs, and annual and perennial herbaceous plants (Table 1). A total of 42 species belonging to 16 families and 39 genera were recorded in the 187 plots. The frequency of occurrence was low for most species, with the value $<10.0 \%$ for 23 species. At the family level, Compositae, Chenopodiaceae, Zygophyllaceae, Leguminosae, and Gramineae were the most abundant families, totally accounting for $61.9 \%$ of the total recorded species. At the species level, herbaceous species (including annual and perennial herbaceous plants) occupied a large proportion of the total recorded species (71\%). The most frequent herbaceous species were 
Halogeton arachnoideus, Artemisia sphaerocephala, Allium mongolicum, Salsola ruthenica, and Zygophyllum fabago, with a frequency of occurrence $>60 \%$ for each. However, at the community level, shrub species (including shrubs and sub-shrubs) represented the major part of the plant communities, covering $90 \%$ of the land surface. The dominant shrub species were Reaumuria songarica and Nitraria sphaerocarpa, with a frequency of occurrence $>90 \%$ for each.

Table 1 Characteristics of the recorded plant species in the sampling plots

\begin{tabular}{|c|c|c|c|c|c|c|c|}
\hline Species name & Family & $\begin{array}{l}\text { Life } \\
\text { form }\end{array}$ & $\begin{array}{c}\text { Frequency } \\
(\%)\end{array}$ & Species name & Family & $\begin{array}{l}\text { Life } \\
\text { form }\end{array}$ & $\begin{array}{c}\text { Frequency } \\
(\%) \\
\end{array}$ \\
\hline Nitraria sphaerocarpa & Zygophyllaceae & Sh & 99 & Chloris virgata & Poaceae & $\mathrm{Ah}$ & 33 \\
\hline Ephedra przewalskii & Ephedraceae & Sh & 6 & Tribulus terrestris & Zygophyllaceae & $\mathrm{Ah}$ & 2 \\
\hline Caragana brachypoda & Leguminosae & Sh & 2 & Chenopodium glaucum & Chenopodiaceae & $\mathrm{Ah}$ & 1 \\
\hline Atraphaxis frutescens & Polygonaceae & Sh & 1 & Allium mongolicum & Liliaceae & $\mathrm{Ph}$ & 66 \\
\hline Tamarix ramosissima & Tamaricaceae & Sh & 1 & Swainsonia salsula & Leguminosae & $\mathrm{Ph}$ & 19 \\
\hline Calligonum mongolicum & Polygonaceae & Sh & 3 & Scorzonera divaricata & Compositae & $\mathrm{Ph}$ & 3 \\
\hline Reaumuria songarica & Tamaricaceae & Ss & 94 & Zygophyllum fabago & Zygophyllaceae & $\mathrm{Ph}$ & 63 \\
\hline Kalidium gracile & Amaranthaceae & Ss & 38 & Arnebia szechenyi & Boraginaceae & $\mathrm{Ph}$ & 28 \\
\hline Zygophyllum xanthoxylon & Zygophyllaceae & Ss & 1 & Astragalus discolor & Leguminosae & $\mathrm{Ph}$ & 12 \\
\hline Asterothamnus centrali-asiaticus & Compositae & Ss & 12 & Artemisia sphaerocephala & Compositae & $\mathrm{Ph}$ & 70 \\
\hline Hedysarum scoparum & Leguminosae & Ss & 2 & Artemisia scoparia & Compositae & $\mathrm{Ph}$ & 17 \\
\hline Sympegma regelii & Chenopodiaceae & Ss & 8 & Artemisia frigida & Compositae & $\mathrm{Ph}$ & 27 \\
\hline Bassia dasyphylla & Chenopodiaceae & $\mathrm{Ah}$ & 26 & Peganum harmala & Zygophyllaceae & $\mathrm{Ph}$ & 2 \\
\hline Halogeton arachnoideus & Chenopodiaceae & $\mathrm{Ah}$ & 93 & Stipa gobica & Poaceae & $\mathrm{Ph}$ & 34 \\
\hline Salsola ruthenica & Amaranthaceae & $\mathrm{Ah}$ & 65 & Cynomorium songaricum & Cynomoriaceae & $\mathrm{Ph}$ & 1 \\
\hline Suaeda microphylla & Chenopodiaceae & $\mathrm{Ah}$ & 2 & Limonium aureum & Plumbaginaceae & $\mathrm{Ph}$ & 9 \\
\hline Agriophyllum squarrosum & Chenopodiaceae & $\mathrm{Ah}$ & 2 & Cynanchum chinense & Asclepiadaceae & $\mathrm{Ph}$ & 1 \\
\hline Echinops gmelini & Compositae & $\mathrm{Ah}$ & 14 & Peganum multisectum & Zygophyllaceae & $\mathrm{Ph}$ & 1 \\
\hline Lappula patula & Boraginaceae & $\mathrm{Ah}$ & 1 & Allium polyrhizum & Alliaceae & $\mathrm{Ph}$ & 1 \\
\hline Neopallasia pectinata & Compositae & $\mathrm{Ah}$ & 1 & Cistanche deserticola & Orobanchaceae & $\mathrm{Ph}$ & 1 \\
\hline Eragrostis pilosa & Poaceae & $\mathrm{Ah}$ & 19 & Achnatherum splendens & Poaceae & $\mathrm{Ph}$ & 1 \\
\hline
\end{tabular}

Note: Sh, shrub; Ss, sub-shrub; Ah, annual herbaceous; $\mathrm{Ph}$, perennial herbaceous.

\subsection{Spatial patterns of plant species diversity indices}

The statistical parameters of the four plant species diversity indices (i.e., Patrick richness index $(R)$, Shannon-Wiener diversity index $\left(H^{\prime}\right)$, Simpson's dominance index $(D)$, and Pielou's evenness index $(J))$ are shown in Table 2. It can be seen that the ranges of $R, H^{\prime}, D$, and $J$ were $2.00-21.00,0.50-1.90,0.18-0.76$, and $0.24-0.94$, respectively. All of those four indices were moderately spatially variable, with the values of CVs (coefficients of variation) ranging between $21.6 \%$ and $40.7 \%$. The coefficients of skewness and kurtosis together with the non-parametric $\mathrm{K}-\mathrm{S}$ tests showed that the statistical distributions of $R$ and $D$ were positively skewed $(P<0.05)$ and that the statistical distributions of $H^{\prime}$ and $R$ were normally distributed $(P>0.05)$. The log-transformed data of both $H^{\prime}$ and $R$, however, passed the K-S tests at the 0.05 significance level and then consequently could be used for the geostatistical analyses.

The CVs of all plant species diversity indices increased with increasing sampling area (Fig. 2). The variations of CVs for $R$ and $D$ with increasing sampling area could be best fitted with power functions, with $R^{2}$ values of 0.82 and 0.94 , respectively $(P<0.05)$. The variations of CVs for $H^{\prime}$ and $J$ with increasing sampling area were best fitted with linear functions, with $R^{2}$ values of 0.84 and 0.60 , respectively $(P<0.05)$. But it should be added that they were also well fitted with power functions, with $R^{2}$ values of 0.75 and 0.51 , respectively $(P<0.05)$. It seems that the power functions may be more theoretically reasonable because the CVs should be zero when the sampling area is zero. 
Table 2 Descriptive statistics of plant species diversity indices

\begin{tabular}{|c|c|c|c|c|}
\hline \multirow{2}{*}{ Statistical parameter } & \multicolumn{4}{|c|}{ Diversity index } \\
\hline & $R$ & $H^{\prime}$ & $D$ & $J$ \\
\hline Maximum & 21.00 & 1.90 & 0.76 & 0.94 \\
\hline Minimum & 2.00 & 0.50 & 0.18 & 0.24 \\
\hline Mean & 9.05 & 1.25 & 0.37 & 0.60 \\
\hline $\mathrm{SD}$ & 3.68 & 0.33 & 0.13 & 0.13 \\
\hline $\mathrm{CV}$ & 40.70 & 26.25 & 35.40 & 21.66 \\
\hline Skewness & 0.37 & -0.18 & 0.86 & -0.08 \\
\hline Kurtosis & -0.31 & -0.51 & 0.06 & -0.31 \\
\hline$P$ of K-S test & 0.044 & 0.098 & 0.003 & 0.375 \\
\hline
\end{tabular}

Note: SD, standard deviation; CV, coefficient of variation; $R$, Patrick richness index; $H^{\prime}$, Shannon-Wiener diversity index; $D$, Simpson's dominance index; $J$, Pielou's evenness index. $n=187$.
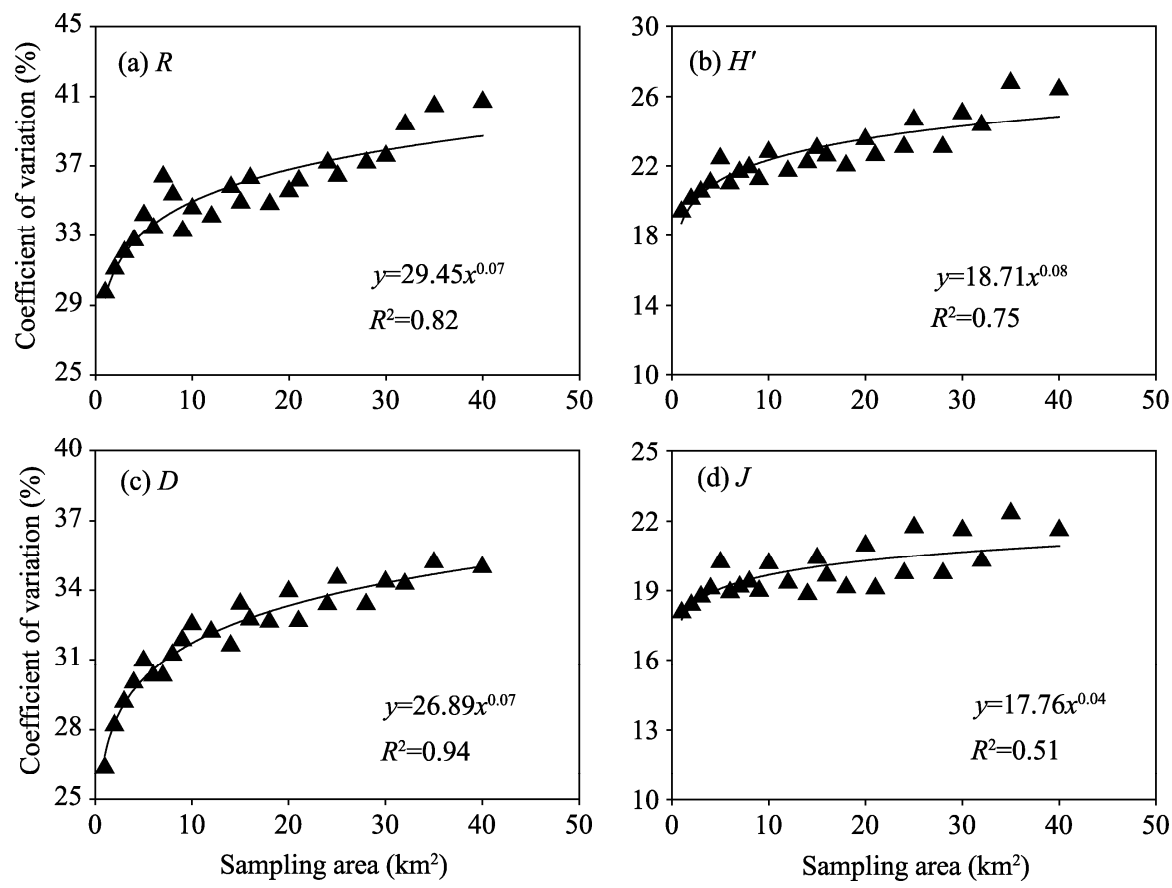

Fig. 2 Relationships of coefficients of variation for the four plant species diversity indices with sampling areas. (a), Patrick richness index (R); (b), Shannon-Wiener diversity index $\left(H^{\prime}\right)$; (c), Simpson's dominance index $(D)$; (d), Pielou's evenness index $(J)$.

The semivariograms for $R$ and $H^{\prime}$ were optimally fitted by Gaussian models, whereas the semivariograms for $D$ and $J$ were best fitted by exponential models (Table 3; Fig. 3). All of the models were satisfactory (with $R^{2}$ values varying from 0.82 to 1.00 ), suggesting that these models can well represent the spatial patterns of plant species diversity indices in the study area.

Table 3 Parameters of the semivariogram models estimated for the four plant species diversity indices

\begin{tabular}{ccccccc}
\hline Diversity index & Model & Nugget $\left(\mathrm{C}_{0}\right)$ & Sill $\left(\mathrm{C}+\mathrm{C}_{0}\right)$ & Nugget ratio $\left(\mathrm{C}_{0} /\left(\mathrm{C}+\mathrm{C}_{0}\right)\right)$ & Range $(\mathrm{A} ; \mathrm{m})$ & $R^{2}$ \\
\hline$R$ & Gaussian & 7.190 & 14.410 & 0.499 & 0.422 & 2981 \\
$H^{\prime}$ & Gaussian & 0.049 & 0.115 & 0.312 & 0.99 \\
$D$ & Exponential & 0.007 & 0.022 & 0.108 & 7890 & 0.99 \\
$J$ & Exponential & 0.002 & 0.017 & 1.00 & 0.82 \\
\hline
\end{tabular}

Note: $R^{2}$, coefficient of determination; $R$, Patrick richness index; $H^{\prime}$, Shannon-Wiener diversity index; $D$, Simpson's dominance index; $J$, Pielou's evenness index. 

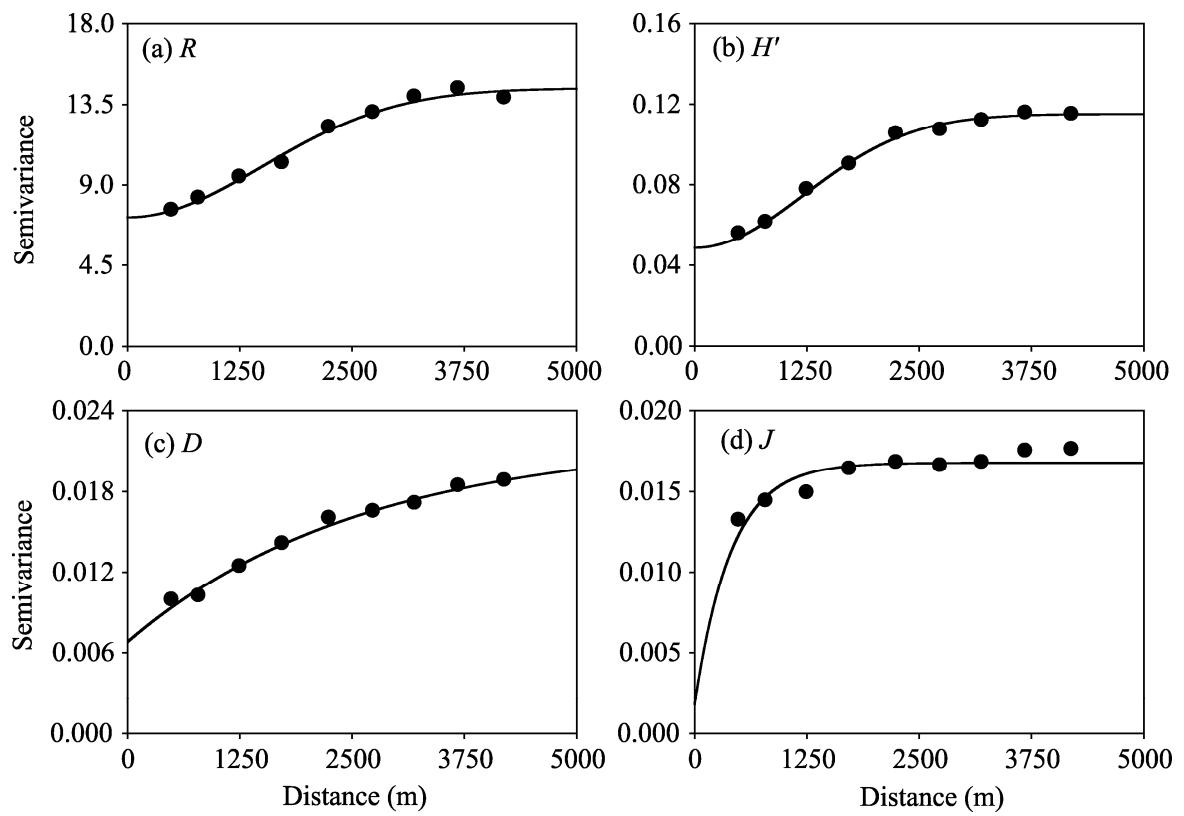

Fig. 3 Semivariograms for the four plant species diversity indices. (a), $R$; (b), $H^{\prime} ;$ (c), $D$; (d), $J$.

Both nugget $\left(\mathrm{C}_{0}\right)$ and sill $\left(\mathrm{C}+\mathrm{C}_{0}\right)$ were higher for $R$ than for other three indices $\left(H^{\prime}, D\right.$, and $\left.J\right)$, which may be attributable to the high value of $R$ itself (Table 3 ). The nugget $\left(\mathrm{C}_{0}\right)$ and sill $\left(\mathrm{C}+\mathrm{C}_{0}\right)$ for other three indices $\left(H^{\prime}, D\right.$, and $\left.J\right)$ varied in the order of $H^{\prime}>D>J$ (Table 3), indicating a higher degree of spatial variability for $H^{\prime}$ than for $D$ and $J$. The nugget ratios $\left(\mathrm{C}_{0} /\left(\mathrm{C}+\mathrm{C}_{0}\right)\right)$ for the four indices indicated moderate spatial autocorrelations for $R, H^{\prime}$, and $D$ (ratios of $0.31-0.50$ ) and a strong spatial autocorrelation for $J$ (ratio of 0.11 ). Furthermore, the spatial autocorrelations (i.e., $D, 7890 \mathrm{~m} ; R, 3681 \mathrm{~m} ; H^{\prime}, 2969 \mathrm{~m}$; and $J, 1218 \mathrm{~m}$ ) indicated that the degree of spatial dependence for the four plant species diversity indices was in the order of $D>R>H^{\prime}>J$.

The spatial patterns of $R$ and $H^{\prime}$ were highly dependent on the location within the study area. Generally speaking, $R$ and $H^{\prime}$ increased gradually from southwest (near the oasis) to north (surrounded by low mountains) and decreased gradually towards the southeastern region that joins with the Badain Jaran Desert (Figs. 4a and b). The spatial pattern of $D$, however, displayed an opposite trend to those of $R$ and $H^{\prime}$, with high $D$ values distributed in the areas near the oasis and desert (Fig. 4c). Being different from the above three indices, $J$ exhibited an irregular spatial pattern (Fig. 4d). As shown in Figure 4d, the plant species were more evenly distributed in the central area.

\subsection{Relationships between plant species diversity indices and environmental factors}

The correlation coefficients for the relationships between plant species diversity indices and environmental factors (including elevation and soil properties) are presented in Table 4, and the correlation coefficients for the relationship between the environmental factors are presented in Table 5. As shown in Table 4, $J$ was not significantly correlated with any of the factors considered $(P>0.05)$, indicating that the differences in the spatial distribution of plant species were not affected by these factors. However, $R, H^{\prime}$, and $D$ were significantly correlated with elevation and all soil properties considered $(P<0.05)$ with an exception of soil organic carbon content $(P>0.05)$, implying that elevation and soil properties (with an exception of soil organic carbon content) play important roles in the spatial variability of plant species diversity. Specifically, $R$ and $H^{\prime}$ were significantly and negatively correlated with silt content $(P<0.01)$, clay content $(P<0.01)$ and total porosity $(P<0.01)$, and were positively correlated with elevation $(P<0.01)$, bulk density $(P<0.01)$, gravel content $(P<0.01)$, sand content $(P<0.01)$, and saturated hydraulic conductivity $(P<0.05)$. Furthermore, the correlations between $D$ and environmental factors were opposite to those for $R$ and $H^{\prime}$ (Table 4 ). 
(a) $R$

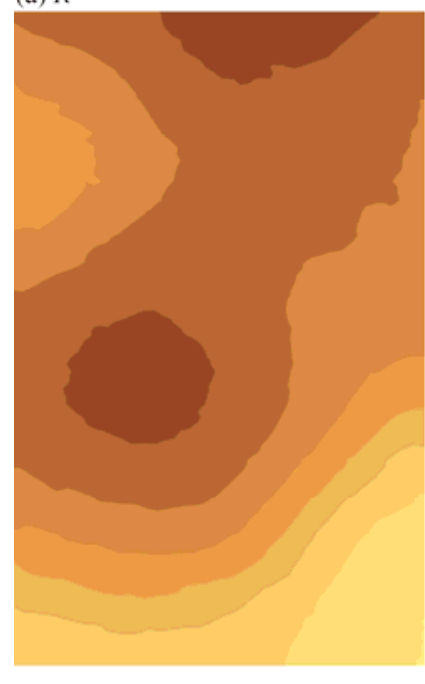

(c) $D$

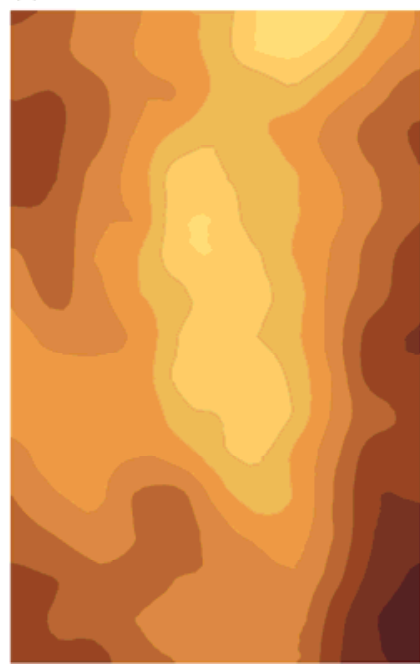

$\stackrel{N}{\Lambda}$

$R$ value

$2.00-3.84$

3.84-5.25

5.25-6.34

$6.34-7.19$

7.19-8.28

$8.28-9.69$

9.69-11.53

11.53-13.91

13.91-17.00

$17.00-21.00$
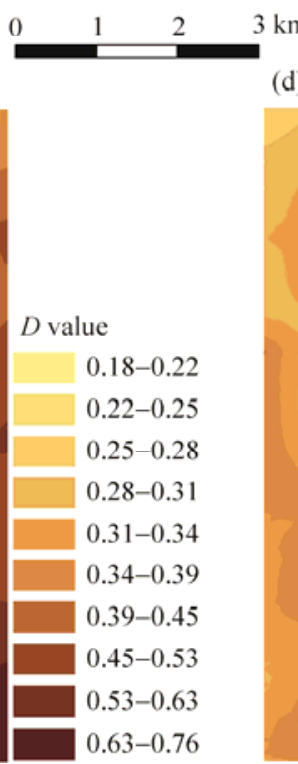

(b) $H^{\prime}$

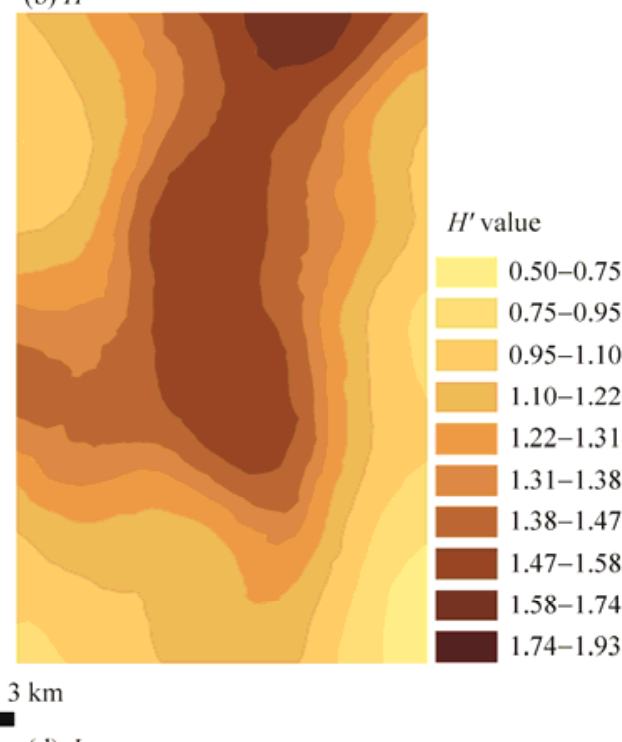

(d) $J$

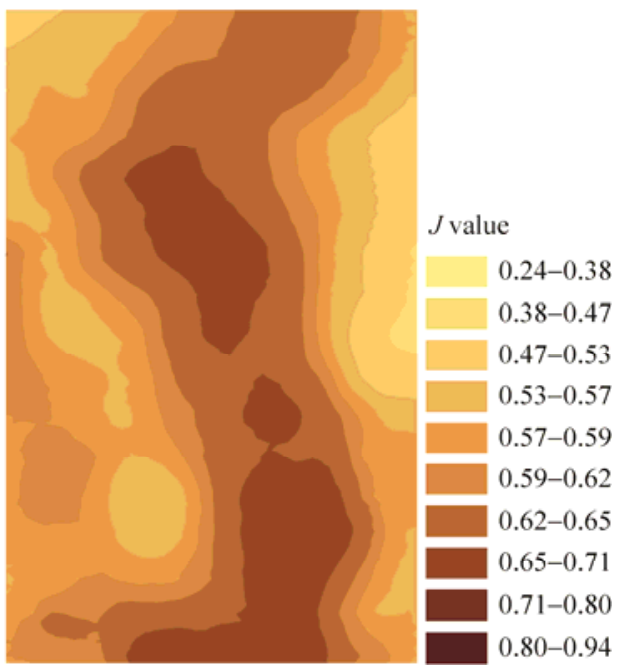

Fig. 4 Spatial patterns of the four plant species diversity indices across the study area. (a), $R ;$ (b), $H^{\prime} ;$ (c), $D$; (d), $J$.

Table 4 Pearson's correlation coefficients between plant species diversity indices and environmental factors

\begin{tabular}{ccccc}
\hline Environmental factor & $R$ & $H^{\prime}$ & $D$ & $J$ \\
\hline Elevation & $0.40^{* *}$ & $0.29^{* *}$ & $-0.26^{* *}$ & -0.07 \\
BD & $0.37^{* *}$ & $0.29^{* *}$ & $-0.24^{* *}$ & -0.05 \\
Gravel & $0.46^{* *}$ & $0.32^{* *}$ & $-0.25^{* *}$ & -0.04 \\
Sand & $0.37^{* *}$ & $0.27^{* *}$ & $-0.20^{* *}$ & -0.08 \\
Silt & $-0.36^{* *}$ & $-0.26^{* *}$ & $0.20^{* *}$ & 0.08 \\
Clay & $-0.37^{* *}$ & $-0.27^{* *}$ & $0.20^{* *}$ & 0.08 \\
SOC & -0.11 & -0.05 & 0.00 & 0.06 \\
Ks & $0.18^{*}$ & $0.18^{*}$ & $-0.14^{*}$ & 0.08 \\
TPo & $-0.38^{* *}$ & $-0.32^{* *}$ & $0.29^{* *}$ & 0.04 \\
\hline
\end{tabular}

Note: BD, bulk density; SOC, soil organic carbon; Ks, saturated hydraulic conductivity; TPo, total porosity. ${ }^{*}$ and ${ }^{* *}$ indicate that the correlation is statistically significant at $P<0.05$ and $P<0.01$ levels, respectively. 
Table 5 Pearson's correlation coefficients among the environmental factors

\begin{tabular}{ccccccccc}
\hline & BD & Gravel & Sand & Silt & Clay & SOC & Ks & TPo \\
\hline Elevation & $0.38^{* *}$ & $0.39^{* *}$ & $0.47^{* *}$ & $-0.47^{* *}$ & $-0.46^{* *}$ & $-0.27^{* *}$ & -0.12 & $-0.41^{* *}$ \\
BD & 1.00 & $0.41^{* *}$ & $0.66^{* *}$ & $-0.67^{* *}$ & $-0.63^{* *}$ & $-0.41^{* *}$ & $0.15^{*}$ & $-0.95^{* *}$ \\
Gravel & & 1.00 & $0.45^{* *}$ & $-0.46^{* *}$ & $-0.43^{* *}$ & $-0.20^{* *}$ & $0.14^{*}$ & $-0.42^{* *}$ \\
Sand & & & 1.00 & $-0.98^{* *}$ & $-0.99^{* *}$ & $-0.68^{* *}$ & $0.18^{*}$ & $-0.70^{* *}$ \\
Silt & & & & 1.00 & $0.95^{* *}$ & $0.68^{* *}$ & $-0.17^{*}$ & $0.73^{* *}$ \\
Clay & & & & & 1.00 & $0.66^{* *}$ & $-0.18^{*}$ & $0.66^{* *}$ \\
SOC & & & & & & 1.00 & $-0.16^{*}$ & $0.43^{* *}$ \\
Ks & & & & & & & 1.00 & $-0.16^{*}$ \\
TPo & & & & & & & & 1.00 \\
\hline
\end{tabular}

Note: ${ }^{*}$ and ${ }^{* *}$ indicate that the correlation is statistically significant at $P<0.05$ and $P<0.01$ levels, respectively.

\section{Discussion}

\subsection{Composition and diversity of plant species}

The shrub species (including shrubs and sub-shrubs) and herbaceous species (including annual and perennial herbaceous plants) in the study area were mainly xerophytes or super-xerophytes. Shrub species generally represented the major part of the plant communities, covering $90 \%$ of the land surface. In contrast, herbaceous species only occurred individually in rather localized spots. However, these herbaceous species occupied a large proportion of the total recorded species (71\%) and thus played important roles in the structure of the plant communities and in the functions of the ecosystems in the study area.

It was previously reported that plant species diversity is high in favorable environments and low in harsh environments (Danin, 1976). Our study area (i.e., a Gobi Desert region) is dominated by a dry climate with low precipitation, high evaporation, and severe wind erosion. These environmental conditions are more suitable for the survival of deep-rooted shrub species (e.g, $R$. songarica and $N$. sphaerocarpa) that have high resistance to drought and sand burial. In contrast, some other shrub and herbaceous species (such as Ephedra przewalskii, Tamarix ramosissima, Peganum multisectum, Lappula patula) can only live in occasionally favorable environmental conditions and can be considered as opportunists. This region had a low species evenness and diversity, precisely because of the higher number of opportunists present and lower number of individuals (Ricotta and Avena, 2003). $H^{\prime}$ in our study area (range of 0.50-1.90) was low and it was generally within the $H^{\prime}$ ranges reported in the other desert regions in China, e.g., the oasis-desert ecotone in Fukang of Xinjiang (0.48-1.57; Zhang et al., 2003), the northeastern Ulan Buh Desert in Inner Mongolia (0.60-2.98; Wang et al., 1996), and the southeastern Tengger Desert in Inner Mongolia (0.60-1.63; Kong and Shen, 2003). Those results indicated that plant species diversity of desert plant communities is universally low.

\subsection{Spatial pattern of plant species diversity}

In this study, all the four plant species diversity indices (i.e., $R, H^{\prime}, D$, and $J$ ) were spatially varying, which can be attributed to the heterogeneity of the environmental factors. Different plant species have different resource niches and can be competitively dominant in different environments (Gundale et al., 2011). The variations in environmental factors will thus result in the spatial variability of species distribution and diversity (Reynolds et al., 2007). Our results demonstrated that plant species diversity was not distributed randomly in space. Instead, they followed distinctive spatial patterns, being rather consistent with the findings of the latest studies (Irl et al., 2015; Fibich et al., 2016). $R, H^{\prime}$, and $D$ exhibited moderate spatial autocorrelations, indicating that the spatial variability of these three indices was regulated by both intrinsic factors (i.e., soil-forming processes) and extrinsic factors (i.e., desert management and human activities). Being different from those three indices above mentioned, $J$ showed a strong spatial 
autocorrelation, which can be attributed to the intrinsic factors (i.e., soil-forming processes).

Our results also showed that the variability of plant species diversity was spatially scale-dependent and was increased with increasing sampling area (size). It was widely reported that environmental factors could influence the distribution of plant species at different spatial scales (e.g., Muñoz-Reinoso and Novo, 2005; Chandy and Gibson, 2009). At large spatial scales, parental material, climate, and geological history are usually the major factors; while at small spatial scales, ecological interaction among the plant species may be the dominant factor. Furthermore, the environmental factors operating at small spatial scales may greatly influence the distribution of plant species at large spatial scales (Zuo et al., 2012). With increasing sampling area, the driving factors of the variability of plant species diversity above mentioned may become increasingly complex and heterogeneous, thus resulting in higher spatial variability of plant species diversity. In this study, the positive power-function relationship between the $\mathrm{CVs}$ of plant species diversity indices and the sampling area indicated that the spatial pattern of plant species diversity was strongly scale-dependent at small spatial scales. This may be due to the discontinuous, patchy, and mosaic distributional patterns of plant species. At small spatial scales, competitive and inter-dependent relationships between plant species are strong in the Gobi Desert region, and many species cluster together to avoid the interference of shifting sand. In contrast, at large spatial scales, due to the flat terrain in the Gobi Desert region, the topographic and hydrogeomorphic conditions are more consistent, thus sampling area (size) is less important in controlling the plant species diversity (He et al., 2006). In our study, an area of $10 \mathrm{~km}^{2}$ seems to be the turning point, below which the influence of the changes in sampling area on the plant species diversity was much more obvious (see Fig. 2). This finding indicated that an area of $10 \mathrm{~km}^{2}$ is an optimal option to represent the plant species diversity and it could be used as a reference size for determining the sampling area in the field investigation in dry desert regions.

\subsection{Influences of environmental factors on plant species diversity}

Variations of plant species diversity are linked with many environmental factors, such as climate, soil, and topography (Huerta-Martínez et al., 2004; Zuo et al., 2012). Due to the small size of the study area, climatic factors were disregarded in this study. The topographical features and soil properties were thus most likely responsible for the spatial pattern of plant species diversity.

Elevation is an important topographical property influencing the spatial pattern of plant species diversity. $R$ and $H^{\prime}$ in our study were significantly and positively correlated with elevations, suggesting that species composition was variable at higher elevations. Previous studies reported that elevation can indirectly regulate the distribution of plant species by influencing the redistribution of soil properties, such as soil moisture, soil nutrients (accumulation and transportation), and soil particle composition ( $\mathrm{Fu}$ et al., 2004; Zuo et al., 2008). The positive relationship of elevation with $R$ and $H^{\prime}$ may be a consequence of the combined contributions of soil properties (Table 5). In fact, the regions at higher elevations in this study were mainly in the transitional zone between the mountains and the Gobi Desert. The micro-topography (such as the runoff gullies) and various soil substrates fragmented the habitats, thus promoting the coexistence of more plant species and increasing the diversity of plant species. In contrast, other previous studies have reported a hump-shaped pattern between species diversity with elevation (Vázquez García and Givnish, 1998; Wang et al., 2003). This discrepancy may be due to the elevation range sampled in the field. The elevation gradients were actually rather small in our study. Moreover, Lomolino (2001) demonstrated that the pattern of diversity-elevation gradients might depend largely on the patterns of co-variation and interaction among the geographically explicit variables.

Soil properties are decisive factors determining the distribution of plant species in arid and semi-arid areas (Maestre et al., 2003). Soil texture and bulk density, the most fundamental physical properties, determine the pore size and shape, and thereby control the exchange and uptake of water, nutrients, and oxygen, thus influencing the growth and distribution of plant species (Arekhi et al., 2010). Gravels in the surface and subsurface soil layers generally modulate 
water infiltration and evapotranspiration, normally increasing the water availability for plant uses (Unger, 1971). As expected, the spatial distribution of plant species diversity in the study area was highly correlated with the aforementioned soil physical properties. As soil silt and clay contents increased and gravel content decreased, soil bulk density and saturated hydraulic conductivity decreased and total porosity increased, resulting in an increase in the moisture-holding capacity of the soil. Generally speaking, wetter habitats always have a higher vegetation cover and biomass ( $\mathrm{Li}$ et al., 2004), which in turn could increase the intensity of species competition and may allow a few species with strong competitive abilities to dominate, thus decreasing the species diversity (Abrams, 1995; Mittelbach et al., 2001). In contrast, the growth of plant species in drier habitats is restricted by coarse-textured soil with lower soil moisture, and species can thus coexist in close proximity without directly competing for resources (Abrams, 1995).

The shelter belts in the study region near the oasis functioned as natural barriers to reduce wind velocity and intercept the fine materials, providing a wetter habitat for a few species, e.g., $N$. sphaerocarpa, $R$. songarica, Kalidium gracile, and H. arachnoideus, which impeded the survival and development of plant species with less competition vigor in this relatively wet habitat. Plant species with less competition vigor were stunted and gradually lost their competitive advantages towards the northern direction (coarse-textured soils with higher contents of gravel and coarse sand). The most representative plant species were $K$. gracile and $H$. arachnoideus and their dominance was resulted from the relatively high soil moisture. Those plant species with less vigor, (e.g., K. gracile, H. arachnoideus, Ephedra przewalskii, Asterothamnus centrali-asiaticus, Allium mongolicum, and Stipa gobica) were thus able to colonize in the northern part, so that the dominant species were not apparent and competitive exclusion did not occur.

In our study, plant species diversity indices were unexpectedly not significantly correlated with soil organic carbon. Other studies, however, have suggested that the distribution of plant species diversity was strongly influenced by soil organic carbon (Yang et al., 2009; Chigani et al., 2012). As reported by Grime (1979), species diversity will be highest at intermediate levels of soil fertility and will be constrained at low levels of soil fertility. Furthermore, high levels of soil fertility may lead to competitive exclusion. Plant growth in this harsh Gobi Desert region (i.e., the study area) may be constrained by many factors, such as the amounts of soil water content and salt content and the availability of soil nutrients (e.g., total nitrogen, and available potassium). The effect of soil organic carbon on species diversity may have been overshadowed by other factors.

\section{Conclusions}

Plant species diversity in the study area was low due to the harsh environmental conditions. Spatial pattern of plant species diversity was most closely correlated with the heterogeneity of elevation and soil properties including texture, bulk density, saturated hydraulic conductivity, and total porosity. Plant species diversity was spatially patterned, and its spatial pattern was depended on the sampling area. Thus, selecting an appropriate sampling area is essential to better identifying the spatial pattern of plant species diversity and understanding the relationships between plant species diversity and environmental factors. We recommend that an area of $10 \mathrm{~km}^{2}$ can be taken as a reference size for selecting the sampling area in desert regions. Due to inter-dependency among plants or the patchy pattern of plants in the Gobi Desert region, plant species diversity was strongly scale-dependent at small spatial scales. The role of plant species diversity at smaller scales in the functioning of desert ecosystems should therefore be fully and routinely determined to maintain the diversity and structure of plant communities in the desert regions.

\section{Acknowledgements}

This study was financially supported by the National Natural Science Foundation of China (91025018) and the Action Plan for West Development Project of Chinese Academy of Sciences (KZCX2-XB3-13). Special thanks go 
to the staff of the Linze Inland River Basin Research Station, Northwest Institute of Eco-Environment and Resources, Chinese Academy of Sciences.

\section{References}

Abrams P A. 1995. Monotonic or unimodal diversity-productivity gradients: what does competition theory predict?. Ecology, 76(7): 2019-2027.

Adams J M, Zhang Y J. 2009. Is there more insect folivory in warmer temperate climates? A latitudinal comparison of insect folivory in eastern North America. Journal of Ecology, 97(5): 933-940.

Arekhi S, Heydari M, Pourbabaei H. 2010. Vegetation-environmental relationships and ecological species groups of the Ilam Oak forest landscape, Iran. Caspian Journal of Environmental Sciences, 8(2): 115-125.

Burgess T M, Webster R. 1980a. Optimal interpolation and isarithmic mapping of soil properties. I. The semi-variogram and punctual kriging. European Journal of Soil Science, 31(2): 315-331.

Burgess T M, Webster R. 1980b. Optimal interpolation and isarithmic mapping of soil properties. II. Block kriging. European Journal of Soil Science, 31(2): 333-341.

Cambardella C A, Moorman T B, Parkin T B, et al. 1994. Field-scale variability of soil properties in central Iowa soils. Soil Science Society of America Journal, 58(5): 1501-1511.

Chandy S, Gibson D. 2009. Scale dependency of species composition and environmental variables in the strata of a deciduous forest. Community Ecology, 10(1): 121-130.

Chigani H K, Khajeddin S J, Karimzadeh H R. 2012. Soil-vegetation relationships of three arid land plant species and their use in rehabilitating degraded sites. Land Degradation \& Development, 23(1): 92-101.

Collins B, Wein G. 1998. Soil heterogeneity effects on canopy structure and composition during early succession. Plant Ecology, 138(2): 217-217.

Costanza J K, Moody A, Peet R K. 2011. Multi-scale environmental heterogeneity as a predictor of plant species richness. Landscape Ecology, 26(6): 851-864.

Danin A. 1976. Plant species diversity under desert conditions. Oecologia, 22(3): 251-259.

Du H Q, Zhou G M, Fan W Y, et al. 2010. Spatial heterogeneity and carbon contribution of aboveground biomass of moso bamboo by using geostatistical theory. Plant Ecology, 207(1): 131-139.

Fibich P, Lepš J, Novotný V, et al. 2016. Spatial patterns of tree species distribution in New Guinea primary and secondary lowland rain forest. Journal of Vegetation Science, 27(2): 328-339.

Fu B J, Liu S L, Ma K M, et al. 2004. Relationships between soil characteristics, topography and plant diversity in a heterogeneous deciduous broad-leaved forest near Beijing, China. Plant and Soil, 261(1-2): 47-54.

Grime J P. 1979. Plant Strategies and Vegetation Processes. Chinchester: John Wiley.

Gundale M J, Fajardo A, Lucas R W, et al. 2011. Resource heterogeneity does not explain the diversity-productivity relationship across a boreal island fertility gradient. Ecography, 34(5): 887-896.

He Z B, Zhao W Z. 2004. Spatial pattern of two dominant shrub populations at transitional zone between oasis and desert of Heihe River Basin. Chinese Journal of Applied Ecology, 15(6): 947-952. (in Chinese)

He Z B, Zhao W Z, Chang X X, et al. 2006. Scale dependence in desert plant diversity. Biodiversity and Conservation, 15(9): 3055-3064.

Huerta-Martínez F M, Vázquez-García J A, García-Moya E, et al. 2004. Vegetation ordination at the southern Chihuahuan Desert (San Luis Potosi, Mexico). Plant Ecology, 174(1): 79-87.

Irl S D H, Harter D E V, Steinbauer M J, et al. 2015. Climate vs. topography-spatial patterns of plant species diversity and endemism on a high-elevation island. Journal of Ecology, 103(6): 1621-1633.

Klute A, Dirksen C. 1986. Hydraulic conductivity of saturated soils. In: Klute A. Methods of Soil Analysis. Madison, WI: ASA and SSSA, 694-700.

Kong L J, Shen J Q. 2003. Analysis on species diversity of plant communities in the southeastern Tenggeli Desert. Journal of Ningxia Agricultural College, 24(4): 25-28, 41. (in Chinese)

Li L, Zhou X Y, Huang Z L, et al. 2006. Study on the relationship between $\alpha$ diversity of plant community and environment on Dinghushan. Acta Ecologica Sinica, 26(7): 2301-2307. (in Chinese)

Li X R, Zhang Z S, Zhang J G, et al. 2004. Association between vegetation patterns and soil properties in the southeastern Tengger Desert, China. Arid Land Research and Management, 18(4): 369-383.

Liu X F, Zhu X F, Pan Y Z, et al. 2016. Vegetation dynamics in Qinling-Daba Mountains in relation to climate factors between 2000 and 2014. Journal of Geographical Sciences, 26(1): 45-58. 
Lomolino M V. 2001. Elevation gradients of species-density: historical and prospective views. Global Ecology and Biogeography, 10(1): 3-13.

Lundholm J T, Larson D W. 2003. Relationships between spatial environmental heterogeneity and plant species diversity on a limestone pavement. Ecography, 26(6): 715-722.

Maestre F T, Cortina J, Bautista S, et al. 2003. Small-scale environmental heterogeneity and spatiotemporal dynamics of seedling establishment in a semiarid degraded ecosystem. Ecosystems, 6(7): 630-643.

Matheron G. 1963. Principles of geostatistics. Economic Geology, 58(8): 1246-1266.

Mittelbach G G, Steiner C F, Scheiner S M, et al. 2001. What is the observed relationship between species richness and productivity? Ecology, 82(9): 2381-2396.

Muñoz-Reinoso J C, Novo F G. 2005. Multiscale control of vegetation patterns: the case of Doñana (SW Spain). Landscape Ecology, 20(1): 51-61.

Nelson D W, Sommers L E. 1982. Total carbon, organic carbon and organic matter. In: Page A L, Miller R H, Keeney D R. Methods of Soil Analysis, Part 2, Chemical and Microbiological Properties. Madison, WI: ASA and SSSA, 534-580.

Peet R K. 1981. Forest vegetation of the Colorado front range. Vegetatio, 45(1): 3-75.

Pellissier L, Fiedler K, Ndribe C, et al. 2012. Shifts in species richness, herbivore specialization, and plant resistance along elevation gradients. Ecology and Evolution, 2(8): 1818-1825.

Reynolds H L, Mittelbach G G, Darcy-hall T L, et al. 2007. No effect of varying soil resource heterogeneity on plant species richness in a low fertility grassland. Journal of Ecology, 95(4): 723-733.

Ricotta C, Avena G. 2003. On the relationship between Pielou's evenness and landscape dominance within the context of Hill's diversity profiles. Ecological Indicators, 2(4): 361-365.

Rodríguez-Castañeda G, Dyer L A, Brehm G, et al. 2010. Tropical forests are not flat: how mountains affect herbivore diversity. Ecology Letters, 13(11): 1348-1357.

Schneider K, Leopold U, Gerschlauer F, et al. 2011. Spatial and temporal variation of soil moisture in dependence of multiple environmental parameters in semi-arid grasslands. Plant and Soil, 340(1-2): 73-88.

Slaton M R. 2015. The roles of disturbance, topography and climate in determining the leading and rear edges of population range limits. Journal of Biogeography, 42(2): 255-266.

Su Y Z, Yang R. 2008. Background concentrations of elements in surface soils and their changes as affected by agriculture use in the desert-oasis ecotone in the middle of Heihe River Basin, North-west China. Journal of Geochemical Exploration, 98(3): 57-64.

Sutherland W J. 1999. Manual of Ecology Survey Methods. Beijing Scientific and Technical Documents Publishing House.

Thuiller W, Lavorel S, Araújo M B, et al. 2005. Climate change threats to plant diversity in Europe. Proceedings of the National Academy of Sciences of the United States of America, 102(23): 8245-8250.

Unger P W. 1971. Soil profile gravel layers: II. Effect on growth and water use by a hybrid forage sorghum. Soil Science Society of America Journal, 35(6): 980-983.

Vázquez García J A, Givnish T J. 1998. Altitudinal gradients in tropical forest composition, structure, and diversity in the Sierra de Manantlán. Journal of Ecology, 86(6): 999-1020.

Wallace C S A, Watts J M, Yool S R. 2000. Characterizing the spatial structure of vegetation communities in the Mojave Desert using geostatistical techniques. Computers \& Geosciences, 26(4): 397-410.

Wang C T, Cao G M, Wang Q L, et al. 2007. Characteristics of artificial grassland plant communities with different establishment duration and their relationships with soil properties in the source region of three rivers in China. Chinese Journal of Applied Ecology, 18(11): 2426-2431. (in Chinese)

Wang G H, Zhou G S, Yang L M, et al. 2003. Distribution, species diversity and life-form spectra of plant communities along an altitudinal gradient in the northern slopes of Qilianshan Mountains, Gansu, China. Plant Ecology, 165(2): 169-181.

Wang J H, Zhou S W, Ren P Z. 1996. Studies on the species diversity of plant communities and their ecotopes in the northeastern Ulan Buh Desert. Journal of Desert Research, 16(3): 258-265. (In Chinese)

Wilson J B, Sykes M T. 1988. Some tests for niche limitation by examination of species diversity in the Dunedin area, New Zealand. New Zealand Journal of Botany, 26(2): 237-244.

Wilson J B, Lee W G, Mark A F. 1990. Species diversity in relation to ultramafic substrate and to altitude in southwestern New Zealand. Vegetatio, 86(1): 15-20.

Xu Y J, Chen Y N, Li W H, et al. 2011. Distribution pattern of plant species diversity in the mountainous Region of Ili River Valley, Xinjiang. Environmental Monitoring and Assessment, 177(1-4): 681-694.

Yang Y H, Chen Y N, Li W H. 2009. Relationship between soil properties and plant diversity in a desert riparian forest in the lower reaches of the Tarim River, Xinjiang, China. Arid Land Research and Management, 23(4): 283-296. 
Yost R S, Uehara G, Fox R L. 1982. Geostatistical analysis of soil chemical properties of large land areas. I. Semi-variograms. Soil Science Society of America Journal, 46(5): 1028-1032.

Zare-Mehrjardi M, Taghizadeh-Mehrjardi R, Akbarzadeh A. 2010. Evaluation of geostatistical techniques for mapping spatial distribution of soil $\mathrm{pH}$, salinity and plant cover affected by environmental factors in Southern Iran. Notulae Scientia Biologicae, 2(4): 92-103.

Zhang L J, Yue M, Zhang Y D, et al. 2003. Characteristics of plant community species diversity of oasis desert ecotone in Fukang, Xinjiang. Scientia Geographica Sinica, 23(3): 329-334. (in Chinese)

Zhang P P, Shao M A. 2015. Spatio-temporal variability of surface soil water content and its influencing factors in a desert area, China. Hydrological Sciences Journal, 60(1): 96-110.

Zhang R, Liu T, Zhang J L, et al. 2016. Spatial and environmental determinants of plant species diversity in a temperate desert. Journal of Plant Ecology, 9(2): 124-131.

Zhang Y J, Adams J, Zhao D H. 2011. Does insect folivory vary with latitude among temperate deciduous forests? Ecological Research, 26(2): 377-383.

Zhao Y Y, Wang Y J, Wang Y Q, et al. 2009. Plant biodiversity of different water conservation forest models and their relationship with soil properties in northern water source area of Chongqing city, southwestern China. Ecology and Environmental Sciences, 18(6): 2260-2266. (in Chinese)

Zuo X A, Zhao H L, Zhao X Y, et al. 2008. Plant distribution at the mobile dune scale and its relevance to soil properties and topographic features. Environmental Geology, 54(5): 1111-1120.

Zuo X A, Zhao X Y, Zhao H L, et al. 2012. Scale dependent effects of environmental factors on vegetation pattern and composition in Horqin Sandy Land, Northern China. Geoderma, 173-174: 1-9. 